\title{
The EBMT activity survey report 2017: a focus on allogeneic HCT for nonmalignant indications and on the use of non-HCT cell therapies
}

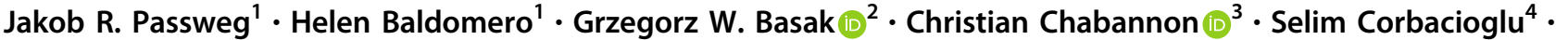 \\ Rafael Duarte ${ }^{5} \cdot$ Jürgen Kuball ${ }^{6}$ - Arjan Lankester $^{7} \cdot$ Silvia Montoto $^{8} \cdot$ Régis Peffault de Latour $^{9} \cdot$ John A. Snowden ${ }^{10}$. \\ Jan Styczynski ${ }^{11}$ - Ibrahim Yakoub-Agha ${ }^{12}$. Mutlu Arat ${ }^{13}$ - Mohamad Mohty ${ }^{14}$. \\ Nicolaus Kröger ${ }^{15} \cdot$ for the European Society for Blood and Marrow Transplantation (EBMT)
}

Received: 21 December 2018 / Accepted: 26 December 2018 / Published online: 6 February 2019

(c) The Author(s) 2019. This article is published with open access

\begin{abstract}
Hematopoietic cell transplantation (HCT) is widely used for acquired and congenital disorders of the hematopoietic system. Number of transplants done in Europe and associated countries continues to rise with 45,418 HCT in 41,100 patients [(17,155 allogeneic (42\%) and 23,945 autologous (58\%)] reported by 683 centers in 50 countries in 2017. Main indications were myeloid malignancies 10,147 (25\%; $96 \%$ allogeneic), lymphoid malignancies 26,488 (64\%; 19\% allogeneic), solid tumors 1,607 (3.9\%; $2 \%$ allogeneic), and nonmalignant disorders 2,667 (7\%; $81 \%$ allogeneic). Trends in donor choice seen before continue, with growing numbers of haploidentical HCT and decreasing use of cord blood. Of interest is that after many years of continued growth, the number of patients receiving an allogeneic HCT for marrow failure is decreasing slightly $(p<0.001)$. Such a change may be explained by the use of thrombopoietin analogs in aplastic anemia patients. Other nonmalignant indications, however continue to grow, most importantly HCT for hemoglobinopathies by $36 \%$, equally for thalassemias and sickle cell disease. Non-HCT cell therapies have increased by $28 \%$ since 2015 and genetically modified $\mathrm{T}$ cells is type of cell therapy with the fastest growth. These annual reports reflect current activity and trends and are useful for health-care planning.
\end{abstract}

Supplementary information The online version of this article (https:// doi.org/10.1038/s41409-019-0465-9) contains supplementary material, which is available to authorized users.

Jakob R. Passweg

jakob.passweg@usb.ch

1 EBMT Activity Survey Office, Hematology, Department of Medicine, University Hospital, Basel, Switzerland

2 Department of Hematology, Oncology and Internal Medicine, Medical University of Warsaw, Warsaw, Poland

3 Institut Paoli Calmettes \& Inserm CBT-1409, Centres d'Investigations Cliniques en Biothérapies, Marseille, France

4 Pediatric Hematology, Oncology and Stem Cell Transplantation Department, Children's Hospital, Regensburg, Germany

5 Servicio de Hematologia y Hemoterapia, Hospital Universitario Puerta de Hierro, Madrid, Spain

6 Department of Haematology, University Medical Centre, Utrecht, The Netherlands

7 BMT Centre, Leiden University Medical Centre Leiden,

\section{Introduction}

Hematopoietic cell transplantation (HCT) is an established procedure for many inherited or acquired disorders of the hematopoietic system, whether benign or neoplastic,

Leiden, The Netherlands

8 St. Bartholomew's Hospital, Barts Health NHS Trust, London, UK

9 BMT Unit, Department of Hematology, Hospital St. Louis, Paris, France

10 Sheffield Teaching Hospitals NHS Foundation, Royal Hallamshire Hospital, Sheffield, UK

11 Pediatric Hematology and Oncology, University Hospital, Collegium Medicum UMK, Bydgoszcz, Poland

12 CHU de Lille, LIRIC, INSERM U995, Université de Lille, 59000 Lille, France

13 Hematopoietic SCT Unit, Florence Nightingale Sisli Hospital, Istanbul, Turkey

14 Department of Hematology, Hospital Saint Antoine, Paris, France

15 Department of Stem Cell Transplantation, University Hospital Eppendorf, Hamburg, Germany 
including those of the immune system, and as enzyme replacement in metabolic disorders [1-4]. The activity survey of the European Society of Blood and Marrow Transplantation (EBMT), describing the status of HCT in Europe and affiliated countries, has become an instrument to observe trends and to monitor changes in technology [5-14]. The survey using a standardized structure captures the numbers of HCT from highly committed participating teams, divided by indication, donor type, and stem cell source. More recently, the survey has included information on novel cell therapies with hematopoietic stem cells for non-hematopoietic use, and the use of non-hematopoietic stem and progenitor cells. This coincides with the interest of the World Health Organization (WHO; www.who.org) in cell and tissue transplants, and further stresses the need for adequate and timely information [15]. The analysis of the survey data spanning 27 years and amassing data on almost 708,000 transplants in over 630,000 patients has shown a continued and constant increase in the annual numbers of HCT and transplant rates for both allogeneic and autologous HCT. This report is based on the 2017 survey data. In addition to transplant rates and indications, it focuses on more recent changes possibly related to development of alternative therapies.

\section{Patients and methods}

\section{Data collection and validation}

Participating teams were invited to report their data for 2017 as listed in Table 1 . The survey allows the possibility to report additional information on the numbers of subsequent transplants performed because of relapse, rejection, or those that are part of a planned sequential transplant protocol.

Additional information on the numbers of donor lymphocyte infusions (DLIs), reduced intensity HCT, and the numbers of pediatric HCT is also collected. Quality control measures included several independent systems: confirmation of validity of the entered data by the reporting team, selective comparison of the survey data with MED-A data sets in the EBMT Registry database, and crosschecking with the National Registries.

\section{Teams}

A total of 720 centers from 50 countries were contacted for the 2017 survey (40 European and 10 affiliated countries); of which 683 teams reported. This corresponds to a $95 \%$ return rate and includes 83\% EBMT members and 17\% non-EBMT members. Thirty-seven active teams failed to report in 2017. Reporting teams are listed in the online appendix in alphabetical order by country, city, and EBMT center code, with their reported numbers of first and total HCT, and of first allogeneic and autologous HCT as supplementary material. The WHO regional office definitions were used to classify countries as European or nonEuropean. Nine neighboring non-European countries participated in the 2017 EBMT survey: Algeria, Iraq, Iran, Israel, Jordan, Lebanon, Saudi Arabia, South Africa, and Tunisia. Their data, 3101 HCT in 2948 patients, from 30 actively transplanting teams make up $6.9 \%$ of the total data set and are included in all analyses.

\section{Patient and transplant numbers}

Wherever appropriate, patient numbers corresponding to the number of patients receiving a first transplant, and transplant numbers reflecting the total number of transplants performed are listed. The term sibling donor includes human leukocyte antigen (HLA) identical siblings and twins but not siblings with HLA mismatches. Unrelated donor transplants include HCT from matched or mismatched unrelated donors with peripheral blood and marrow as a stem cell source but not cord blood HCT. Haploidentical transplants are being described as any family member with 2 or more loci mismatch within the loci HLA$\mathrm{A},-\mathrm{B},-\mathrm{C},-\mathrm{DRB} 1$, and -DQB1 in graft versus host $(\mathrm{GvH})$ and/or host versus graft direction. Other family member donors are those related donors that are mismatched to a lesser degree than a full haplotype. Additional non-first transplants may include multiple transplants defined as subsequent transplants within a planned double or triple autologous or allogeneic transplant protocol, and retransplants (autologous or allogeneic) defined as unplanned HCT for rejection or relapse after a previous HCT.

\section{Transplant rates}

Transplant rates, defined as the total number of HCT per 10 million inhabitants, were computed for each country without adjustments for patients who crossed borders and received their HCT in a foreign country. Population numbers for the European countries in 2017 were obtained from Eurostats (http://epp.eurostat.ec.europa.eu) and from the US census bureau database for the non-European countries (https://www.census.gov/data-tools).

\section{Analysis}

Wherever appropriate, the absolute numbers of transplanted patients, transplants, or transplant rates are shown for specific countries, indications, or transplant techniques. Myeloid malignancies include acute myeloid leukemia (AML), myelodysplastic or myelodysplastic/myeloproliferative neoplasm (MDS or MD/MPN overlap), myeloproliferative 


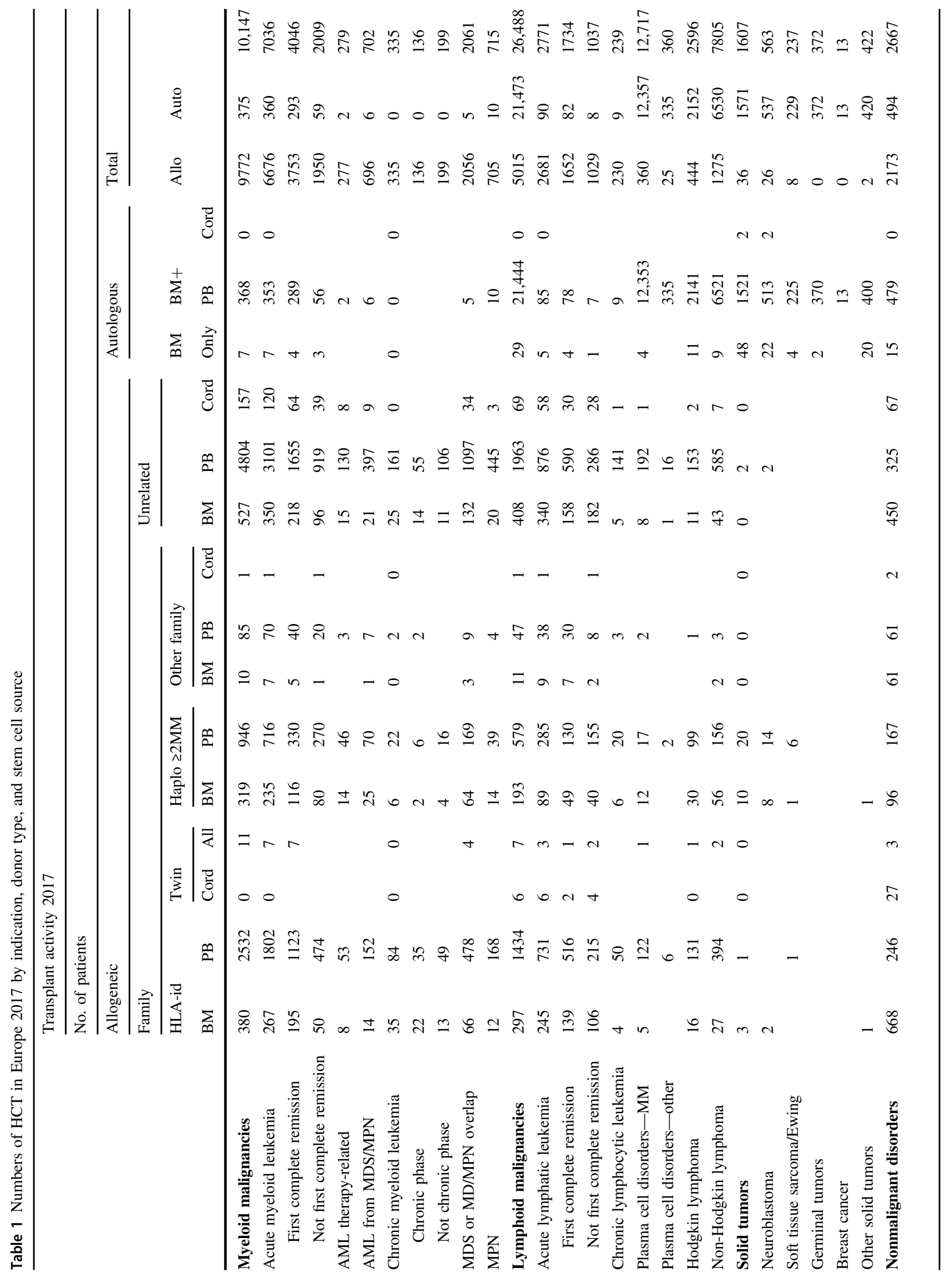




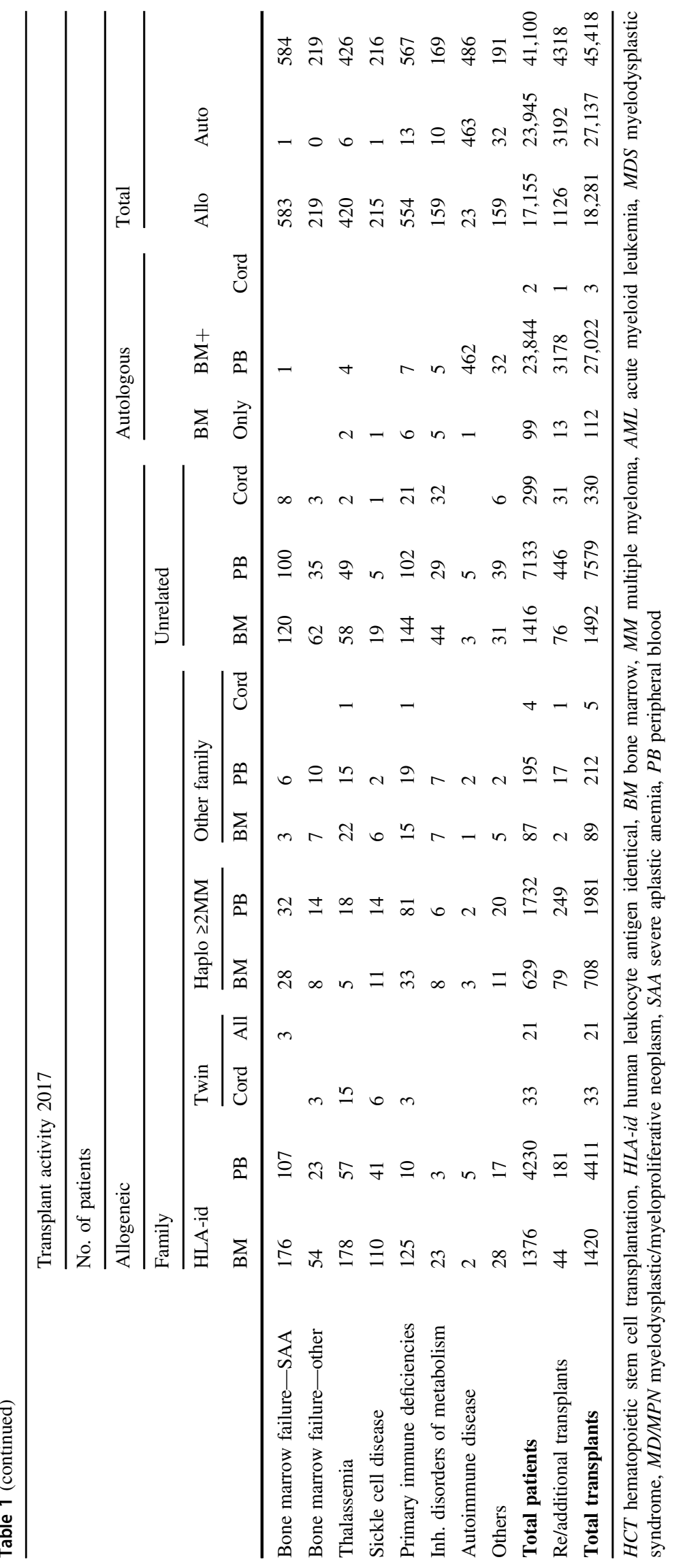


neoplasm (MPN), and chronic myeloid leukemia (CML). Lymphoid malignancies include acute lymphocytic leukemia (ALL), chronic lymphocytic leukemia (CLL), Hodgkin lymphoma (HL), non-Hodgkin lymphoma (NHL), and plasma cell disorders (PCD including multiple myeloma (MM) and others). The nonmalignant disorders include bone marrow failure (BMF including severe aplastic anemia (SAA) and others), thalassemia and sickle cell disease (HG), primary immune disease, inherited disease of metabolism, and autoimmune disease (AID). Others include histiocytosis and rare disorders not included in the above. BMF syndromes were grouped until 2004, at which time they were separated into SAA and other marrow failure. Trends shown over time include changes in absolute number of patients transplanted from 1990 to 2017. We use graphical representation to indicate changes over time. We consider an increase or decrease of $\pm 5 \%$ as a non-relevant change. To confirm trends we used SPSS to automatically fit the best exponentially smoothed, autoregressive integrated moving average model without any further prespecification. To detect possible deviations from trends, we calculated the observed and predicted counts as well as the 95\% confidence intervals (CIs).

\section{Results}

\section{Participating teams in 2017}

Of the 683 teams, $430(63 \%)$ performed both allogeneic and autologous transplants; $236(34 \%)$ restricted their activity to autologous HCT, and 17 (2\%) to allogeneic transplants only. Of the 683 active centers, 131 (19\%) centers performed transplants on both adult and pediatric patients. An additional $115(17 \%)$ centers were dedicated pediatric transplant centers and 437 (64\%) centers performed transplants on adults only. Thirty-seven teams failed to report in 2017, which when compared to previously reported data by these teams, accounts for approximately 630 non-reported HCT.

\section{Numbers of patients and transplants}

In 2017, 45,418 transplants were reported in 41,100 patients (first transplant); of these, 18,281 HCT (40\%) were allogeneic and 27,137 (60\%) autologous (Table 1). When compared with 2016 the total number of transplants increased by $4.1 \%$ (3.6\% allogeneic HCT and $4.4 \%$ autologous HCT) [16]. In patients receiving their first transplant in 2017, the increase was $3.9 \%$ for allogeneic HCT and $5.0 \%$ for autologous HCT. In addition, there were 4318 second or subsequent transplants, 1126 being allogeneic, mainly to treat relapse or graft failure and 3192 autologous, the majority of which were most likely part of multiple transplant procedures such as either tandem procedures, or as salvage autologous transplants for plasma cell disorders. Furthermore, 986 of the allogeneic HCTs were reported as being given after a previous autologous HCT, and were mainly for lymphoma or plasma cell disorders.

The total number of patients transplanted under the age of 18 in both dedicated and joint adult-pediatric units was 5056 (3725 allogeneic and 1331 autologous). This is an increase of $7.8 \%$ (5.1\% allogeneic and $16.2 \%$ autologous) when compared to 2016, where 4690 HCT (3545 allogeneic and 1145 autologous) were reported. From the 5056 patients, 3983 transplants in 3505 patients (2701 allogeneic, 77\%; and 804 autologous, 23\%) were performed in dedicated pediatric centers. Due to limitations in the design of the survey, indication for HCT can only be observed in the dedicated pediatric centers. The main indications were myeloid malignancies 588 (17\%; 99\% allogeneic), lymphoid malignancies 851 (24\%; 86\% allogeneic), solid tumors 696 (20\%; 4\% allogeneic), and nonmalignant disorders 1370 (39\%; 99\% allogeneic). When compared to 2016, increases in allogeneic HCT were seen in sickle cell disease (55.8\%), thalassemia (40.4\%), ALL (12.8\%), and AML (9.6\%). For autologous HCT the main increase was seen in HL (30\%) and pediatric solid tumors (17.5\%).

\section{Indications and trends}

Indications for HCT in 2017 are listed in detail in Table 1. Main indications for HCT were myeloid malignancies (AML, CML, MDS or MD/MPN overlap, and MPN): 10,147 (25\% of total; $96 \%$ of which were allogeneic); lymphoid malignancies (ALL, CLL, HL, NHL, and PCD): 26,488 (64\%; $19 \%$ allogeneic); solid tumors: 1607 (4\%; $2 \%$ allogeneic); nonmalignant disorders: 2667 (7\%; 81\% allogeneic), and others: $191(0.5 \%)$. As seen in previous years, the majority of HCT for lymphoid malignancies were autologous, while most transplants for myeloid malignancies were performed using stem cells from allogeneic donors. Autologous HCT for nonmalignant disorders predominantly include patients with autoimmune disorders.

Figure 1a, b shows distribution of disease indications for allogeneic (Fig. 1a) and autologous (Fig. 1b) HCT as a pie graph. For comparative analyses, the 2017 data are juxtaposed to the analogous data from the years 2007 and 1997 using the size of the pie graph to represent the absolute number of transplanted patients and the pie slices for proportions of specific indications [9, 17]. The 2017 data are used to depict the pie graph with the $100 \%$ size for allogeneic and autologous HCT respectively, pie size for 2007 and 1997 are proportionally smaller.

As shown (Fig. 1a), the number of patients treated with an allogeneic HCT has increased from 4751 to 17,155 over 
a
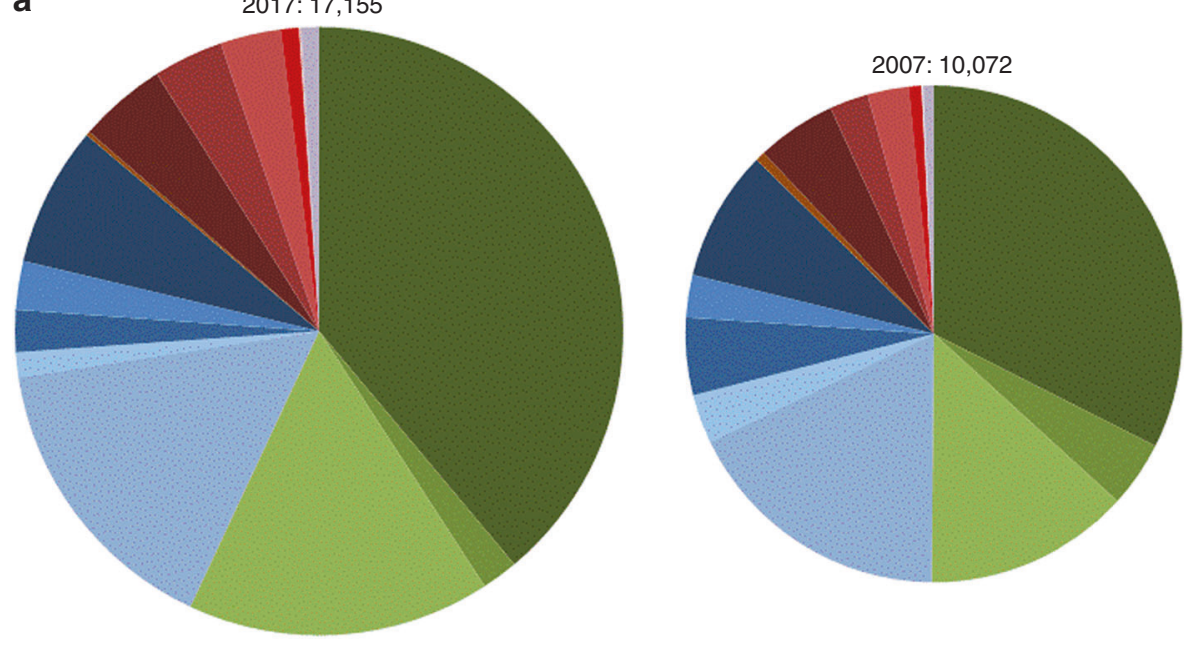

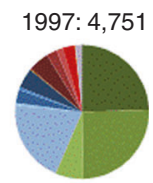

\begin{tabular}{|l|c|c|c|}
\hline & \multicolumn{3}{|c|}{ Proportion of allogeneic HCT over time } \\
\cline { 2 - 4 } & 2017 & 2007 & 1997 \\
\hline Acute myeloid leukemia & 38.9 & 32.5 & 24.5 \\
\hline Chronic myeloid leukemia & 2.0 & 4.3 & 25.3 \\
\hline Myeloproliferative disorders & 16.1 & 13.4 & 6.8 \\
\hline Acute lymphatic leukemia & 15.6 & 17.7 & 20.0 \\
\hline Chronic lymphocytic leukemia & 1.3 & 3.2 & 0.7 \\
\hline Plasma cell disorder & 2.2 & 5.0 & 3.2 \\
\hline Hodgkin lymphoma & 2.6 & 2.8 & 0.7 \\
\hline Non hodgkin lymphoma & 7.4 & 8.5 & 4.8 \\
\hline Other solid tumor & 0.2 & 0.6 & 0.3 \\
\hline Bone marrow failure & 4.7 & 5.2 & 5.0 \\
\hline Hemoglobinopathies & 3.7 & 2.5 & 2.6 \\
\hline Primary immune disorders & 3.2 & 2.7 & 1.7 \\
\hline Inherited disorders of metabolism & 0.9 & 0.8 & 2.8 \\
\hline Auto immune disorders & 0.1 & 0.1 & 0.1 \\
\hline Others & 0.9 & 0.7 & 1.6 \\
\hline
\end{tabular}

b
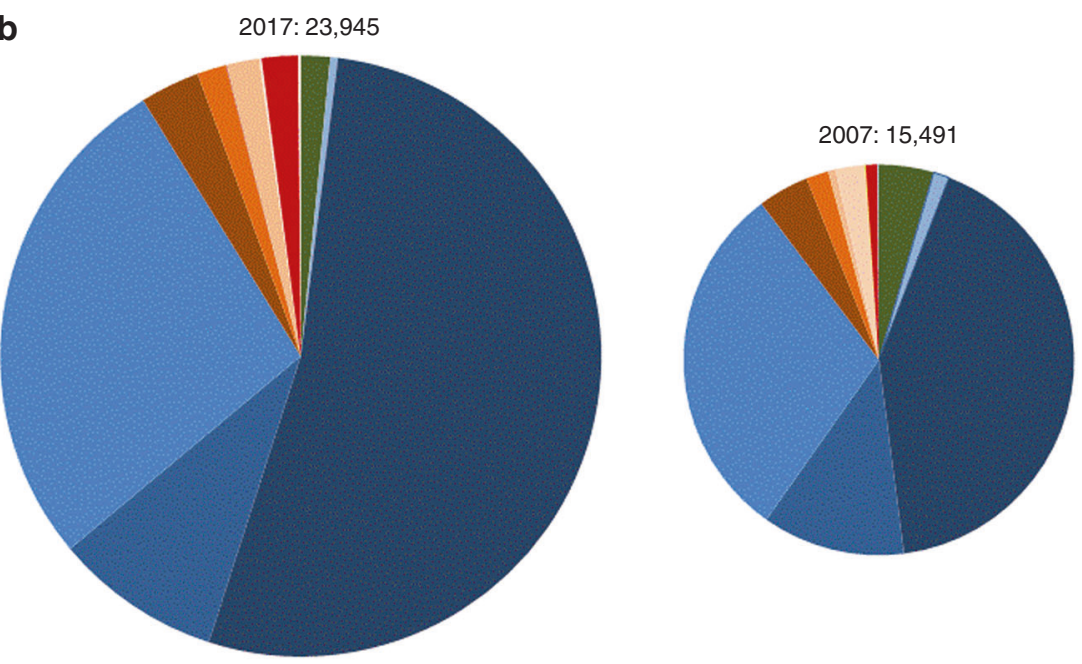

1997: 12199

\begin{tabular}{|l|c|c|c|}
\hline & \multicolumn{3}{|c|}{ Proportion of autologous HCT over time } \\
\cline { 2 - 4 } & 2017 & 2007 & 1997 \\
\hline Myeloid disorders & 1.6 & 4.5 & 9.2 \\
\hline Acute lymphatic and chronic lymphocytic leukemia & 0.4 & 1.3 & 3.8 \\
\hline Plasma cell disorder & 53.0 & 42.0 & 18.3 \\
\hline Hodgkin lymphoma & 9.0 & 11.8 & 8.7 \\
\hline Non hodgkin lymphoma & 27.3 & 29.9 & 25.1 \\
\hline Pediatric solid tumors & 3.2 & 4.2 & 5.2 \\
\hline Germ cell tumors & 1.6 & 1.9 & 4.3 \\
\hline Breast cancer & 0.1 & 0.6 & 21.5 \\
\hline Other solid tumors & 1.8 & 2.5 & 3.0 \\
\hline Non malignant disorders & 0.1 & 0.1 & 0 \\
\hline Auto immune disorders & 1.9 & 1.0 & 0.2 \\
\hline Others & 0.1 & 0.1 & 0.7 \\
\hline & 100 & 100 & 100 \\
\hline
\end{tabular}

Fig. 1 Relative proportion of disease indications for hematopoietic cell transplantation (HCT) in Europe between the years 1997, 2007 , and 2017. a Relative proportion of allogeneic HCT. b Relative proportion of autologous HCT 
20 years. For allogeneic HCT, AML is the most frequent indication (39\%), of these $56 \%$ were for patients in CR1, $29 \%$ for patients with more advanced disease, and $15 \%$ for patients with transformed AML, either therapy-related or from MDS/MPN. The 20-year trend confirms the decline in HCT for CML from 25.3 to $1.9 \%$, whereas AML, MDS, and MPN have increased substantially. The proportion of ALL transplants has decreased only slightly, other lymphoid malignancies have rather increased. Compared to 2016, there were increases in allogeneic HCT for AML by $6.3 \%$, and MDS and MPN by $9.5 \%$ and $9.0 \%$, respectively. HL increased by $13.8 \%$, and thalassemia and sickle cell disease by $27.7 \%$ and $56.9 \%$, respectively. Decreases were seen for CML by $12.8 \%$, PCD by $16.9 \%$, CLL by $16.4 \%$, and BMF by $10.3 \%$.

In Fig. 1b for autologous HCT, the number of patients has increased from 12,199 to 23,945 (an increase of 196\% over 20 years as compared to allogeneic HCT where the increase is $360 \%$ over 20 years). In autologous HCT, PCD is the most frequent indication (53\%), of these $51.5 \%$ were for MM. Compared to 2016, there were increases in autologous HCT for AID by $31.9 \%$, neuroblastoma by $12.1 \%$, soft tissue and Ewing sarcoma by $20.5 \%$, and MM by $7.0 \%$. In autologous HCT, myeloma has become the dominant indication increasing from 18 to $53 \%$ over the past 20 years. Proportions of HCTs for HL and NHL have remained stable. Autologous HCT for AML has decreased from 13 to $1.72 \%$. Already well described is the change in autologous HCT for solid tumor where the decrease in use of this technology in breast cancer dominates the graphical representation.

Within allogeneic HCT 7166 were performed using nonmyeloablative conditioning in 2017. This comprises 39\% of all allogeneic HCT, and has remained stable over the last 9 years. European maps depicting transplant rates by country are provided in the supplementary figures section (supplementary Figure 1a for allogeneic, $1 \mathrm{~b}$ for autologous)

\section{Nonmalignant disorders}

Figure 2 depicts allogeneic HCT numbers for nonmalignant disorders. Since 2016, an increase in numbers of HCT for hemoglobinopathies (sickle cell disease by $56.9 \%$ and thalassemia by $27.7 \%$ ) and inherited disorders of metabolism by $6.0 \%$ has been observed with stable numbers for primary immunodeficiencies and AID. The increase for sickle cell disease HCT is clearly ( $>95 \%$ CI for the prediction model) significant, for thalassemia of borderline significance. A decline in the numbers of HCT is seen for BMF by $10.3 \%$. This decline is still borderline within the lower confidence limits of the prediction model but after many years of increasing HCT numbers for marrow failure this is the first time that numbers actually do decline. This is likely due to

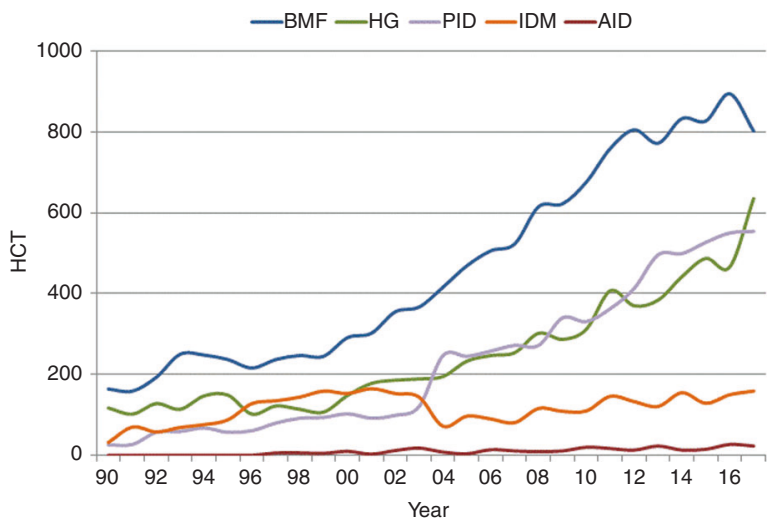

Fig. 2 Trends in the absolute numbers of allogeneic hematopoietic cell transplantation (HCT) for nonmalignant disorders in Europe 1990-2017

the use of thrombopoietin analogs recently approved to treat refractory aplastic anemia.

Autologous HCT (not shown in the figure) is predominantly used for the treatment of AIDs, where a continuous increase has been seen for the last 12 years. Compared to 2016, the increase is $32 \%$. This recent increase is however mainly due to one non-EBMT member center in Eastern Europe reporting large numbers of autologous HCT for multiple sclerosis.

We now focus on marrow failure, where Fig. 3a shows recent changes in practice for BMF: types of donors used indicate that the use of sibling and unrelated donor transplants are decreasing by $15 \%$ and $8 \%$ respectively. Whilst the numbers of haploidentical HCT for marrow failure remain stable, the number of cord blood transplants performed is very low. In marrow failure, the use of marrow is generally recommended over the use of peripheral blood as a stem cell source, mainly because of the absence of benefit of potentially higher alloreactivity conferred by the higher number of $\mathrm{T}$ lymphocytes in the peripheral blood graft $[18,19]$. Figure $3 b$ shows the changes in stem cell source for sibling donor HCT, $3 \mathrm{c}$ for unrelated donor HCT, and $3 \mathrm{~d}$ for haploidentical HCT. Marrow is the preferred source of stem cells in sibling donor HCT but is less so in unrelated donor HCT. In haploidentical HCT for marrow failure, slightly more peripheral blood HCT is performed when compared to marrow. Marrow failure syndromes are rare diseases and the experience of teams doing these transplants is evidently limited. Table 2 shows the number of transplants for BMF by type of donor and the number of teams performing these transplants. Of note, e.g., in haploidentical HCT the 108 patients receiving transplants were treated in 64 different centers, the median number of haploidentical HCT per team is 1 (range 1-9). Over 100 patients received haploidentical HCTs for marrow failure in spite of a very limited number of published series [20-23] in the field. European maps depicting transplant rates by country 


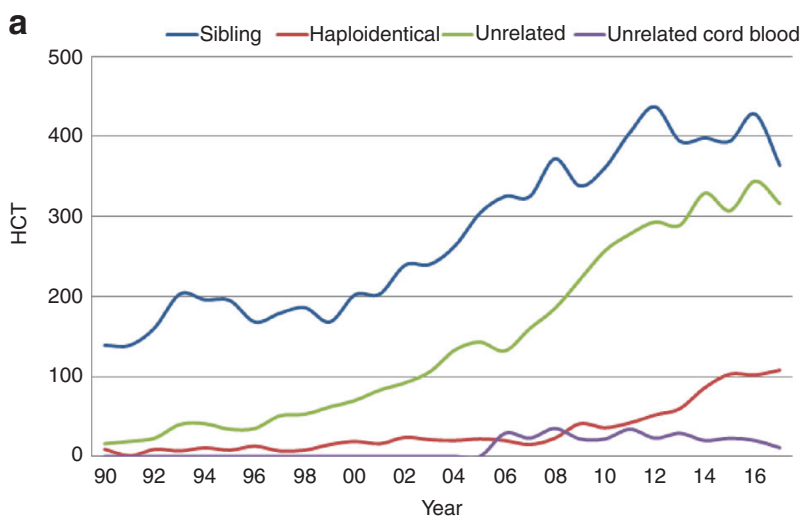

C

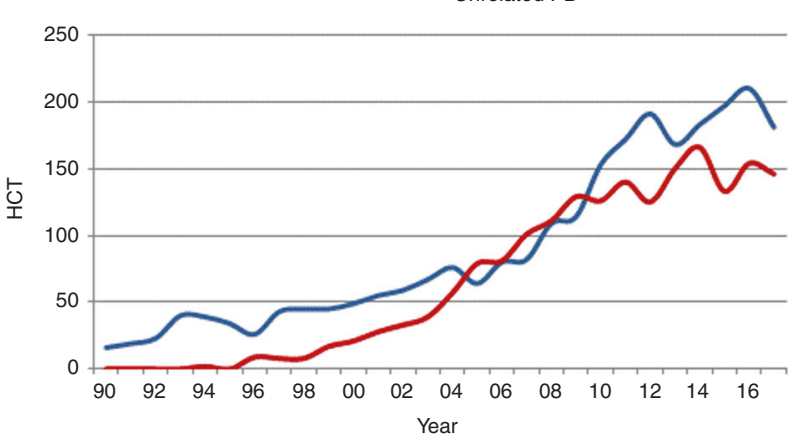

Fig. 3 Changes in donor choice and stem cell source for bone marrow failure in Europe 1990-2017. a Donor choice. b Human leukocyte antigen identical sibling hematopoietic cell transplantation (HCT) by

Table 2 BMF data by center in 2017

\begin{tabular}{llll}
\hline & HCT, $N$ & Teams, $N$ & Median and range \\
\hline Sibling & 363 & 168 & $1(1-20)$ \\
Unrelated & 317 & 163 & $1(1-8)$ \\
Haploidentical & 108 & 64 & $1(1-9)$ \\
Cord blood & 14 & 14 & $1(1)$ \\
Total & 802 & & \\
\hline
\end{tabular}

$B M F$ bone marrow failure, $H C T$ hematopoietic cell transplantation

are provided in the Supplementary Figures section. Supplementary Figure 1a shows allogeneic transplant rates per country for all indications. Whereas the map depicting allogeneic HCT reflects income class of countries, wealthier countries usually having higher rates than middle-income countries, transplant rates for marrow failure look somewhat different. The countries with the highest reported rates for marrow failure transplants include Lithuania, Norway, Ireland, Turkey, and Israel.

\section{Cell therapy}

Table 3 shows cell therapies performed in EBMT centers in 2017. There were 2825 patients receiving DLIs, which is a b

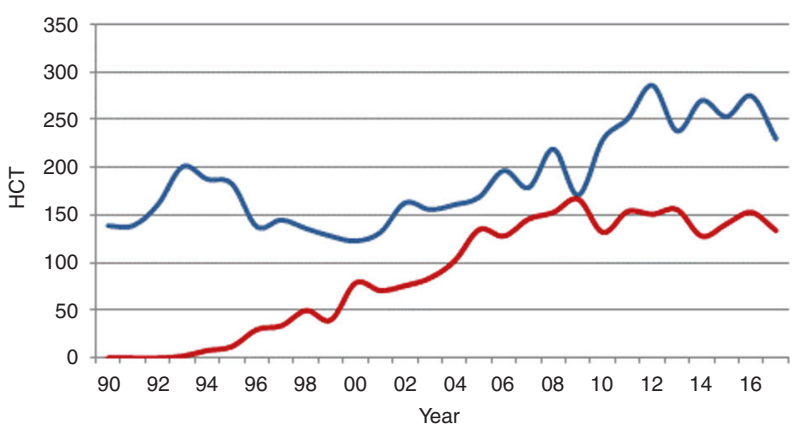

d

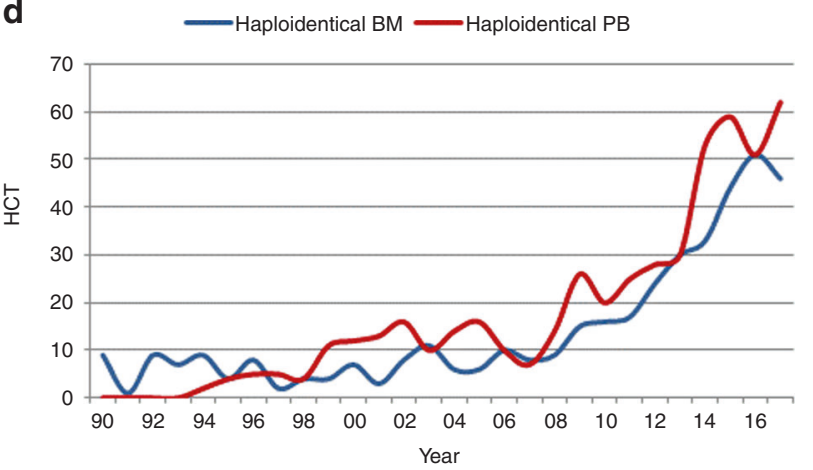

bone marrow (BM) or peripheral blood (PB). c Unrelated HCT by BM or PB. d Haploidentical HCT by BM or PB

slight decrease of $1.9 \%$ since 2016 where 2879 DLIs were reported. The majority of DLIs were given for relapse (1284) and graft enhancement (661). Other reasons being for residual disease (422) and "per protocol" (458). A total of 1202 patients received other forms of cell therapy, most commonly mesenchymal stromal cells $(n=557$; $91 \%$ allogeneic), mainly to treat GvH disease (GvHD). Expanded/ selected T lymphocytes $(n=179 ; 100 \%$ allogeneic $)$ and genetically modified T cells ( $n=151 ; 50 \%$ allogeneic) were the second most frequently reported cell therapy. The area with the highest growth is genetically modified $\mathrm{T}$ cells. The main indications for cell therapies (excluding DLI) being GvHD or graft enhancement ( $n=688 ; 95 \%$ allogeneic), malignancy $(n=253 ; 50 \%$ allogeneic), infections ( $n=124$; $100 \%$ allogeneic), AID ( $n=61 ; 43 \%$ allogeneic $)$, and genetic disease ( $n=14 ; 7 \%$ allogeneic). The number of cell therapies have increased by $27.6 \%$ since 2015 , when they were first introduced into the survey $(2015, \mathrm{HCT}=942$; and 2017, HCT = 1202) [24, 25].

\section{Discussion}

The EBMT activity survey has been conducted annually since 1990 [7]. The 2010 survey reported for the first time 
Table 3 Non-HCT cellular therapies using manipulated cells in 2017

\begin{tabular}{|c|c|c|c|c|c|c|c|c|c|c|c|c|c|c|c|c|c|c|c|}
\hline \multirow[t]{2}{*}{ Number of patients } & \multirow[t]{2}{*}{ DLI } & \multicolumn{2}{|c|}{ MSC } & \multicolumn{2}{|c|}{ NK cells } & \multicolumn{2}{|c|}{$\begin{array}{l}\text { Selected/ } \\
\text { expanded } \\
\mathrm{T} \text { cells or } \\
\mathrm{CIK}\end{array}$} & \multicolumn{2}{|c|}{ TREGS } & \multicolumn{2}{|c|}{$\begin{array}{l}\text { Geneti- } \\
\text { cally } \\
\text { modified } \\
\text { T cells }\end{array}$} & \multicolumn{2}{|c|}{$\begin{array}{l}\text { Dendritic } \\
\text { cells }\end{array}$} & \multicolumn{2}{|c|}{$\begin{array}{l}\text { Expanded } \\
\text { CD34+ } \\
\text { cells }\end{array}$} & \multicolumn{2}{|c|}{$\begin{array}{l}\text { Geneti- } \\
\text { cally } \\
\text { modified } \\
\text { CD34+ } \\
\text { cells }\end{array}$} & \multicolumn{2}{|c|}{ Other } \\
\hline & & Allo & Auto & Allo & Auto & Allo & Auto & Allo & Auto & Allo & Auto & Allo & Auto & Allo & Auto & Allo & Auto & Allo & Auto \\
\hline GvHD & & 413 & 5 & & & 8 & & 36 & & & & & & & & & & 13 & \\
\hline Graft enhancement & 661 & 55 & 18 & 1 & & 14 & & 5 & & 57 & & & 4 & 6 & & 1 & & 44 & 8 \\
\hline Autoimmune disease & & 6 & 14 & 19 & & & & & & & & & & 1 & & & & & 21 \\
\hline Genetic disease & & 1 & & & & & & & & & & & & & & & 13 & & \\
\hline Infection & & 3 & & & & 113 & & & & & & & & & & & & 8 & \\
\hline Malignancy & & & & 6 & & 42 & & 24 & 8 & 16 & 78 & 5 & 35 & 2 & & & & 32 & 5 \\
\hline $\begin{array}{l}\text { DLI for residual } \\
\text { disease }\end{array}$ & 422 & & & & & & & & & & & & & & & & & & \\
\hline DLI for relapse & 1284 & & & & & & & & & & & & & & & & & & \\
\hline DLI per protocol & 458 & & & & & & & & & & & & & & & & & & \\
\hline $\begin{array}{l}\text { Regenerative } \\
\text { medicine }\end{array}$ & & 31 & 11 & 1 & & 2 & & & & & & & & 2 & & & & 4 & 11 \\
\hline Total & 2825 & 509 & 48 & 27 & 0 & 179 & 0 & 65 & 8 & 73 & 78 & 5 & 39 & 11 & 0 & 1 & 13 & 101 & 45 \\
\hline
\end{tabular}

more than 30,000 patients transplanted in a given year, $>40,000$ transplants in 2014, and >45,000 in 2017. As before, autologous HCT continues to expand (4.4\%) and at a higher rate than allogeneic HCT $(3.6 \%)$. In allogeneic HCT, some indications continue to increase but not others. Impressive changes are observed in nonmalignant disorders, there were considerable increases of allogeneic HCT for hemoglobinopathies, including the thalassemias and sickle cell disease. The majority of which is with matched sibling donors and among sibling donor HCT, $73 \%$ is with marrow as a stem cell source. For the first time we describe a lower number of transplants for marrow failure. Such a decrease coincides with the approval of the thrombopoietin mimetic eltrombopag for relapsed refractory aplastic anemia [21]. Next to aplastic anemia, decreased use of allogeneic HCT was also seen in CLL and PCD by almost $20 \%$, which is best explained by the competition of new drugs being developed in these fields. Therefore, it seems that the use of allogeneic HCT is modified by availability of drugs to treat the disease. Furthermore, such shifts in use of transplant technology occur rather rapidly.

In autologous HCT, the only striking increase is in HCT for AID, which has increased by almost a third since 2016, mostly related to autologous HCT to treat multiple sclerosis [26].

We have generated pie graphs showing number of transplants as pie size and proportion of indications by segment over the last 20 years. Of interest is that some of the proportions have remained stable over the years, e.g., allogeneic HCT for ALL. While, as described before, CML has decreased dramatically as a main indication. It appears to have been replaced in much greater numbers, but in similar proportions, by MDS and more recently MPN and AML. Whether this shift in indications is biased by the availability of treatment resources, or follows some other logic, is difficult to discern.

For marrow failure, interesting aspects include the resolute resistance in the use of peripheral blood over marrow. This is seen more so with unrelated donor HCT than with sibling donor transplantation, and may possibly be related to the unwillingness of some unrelated donors to undergo marrow harvest. The use of haploidentical HCT for marrow failure is not substantiated by much available data, and the reason for this use of technology may be due to the general popularity of haploidentical HCT in recent years.

The section on cell therapies shows the gradual increasing use of mesenchymal stromal cells, most commonly to treat GvHD. There is a large increase in the use of gene modified T cells from 36 in 2016 to 151 in 2017. Whether these numbers reflect all patients receiving genemodified $\mathrm{T}$ cells in Europe during the year is not entirely clear, as some centers may not report patients treated in clinical trials. It is our goal to truly reflect the activity of this rapidly growing field within Europe. As CAR-T cells [27] have become commercially available in 2018, it is most important that EBMT centers continue the wellestablished practice of transparently sharing data on activity of advanced therapy medicinal products manufactured from hematopoietic cells used and on the outcome of patients. These data reflect the ability of the EBMT to capture data not only on HCT but also on nonHCT cell therapies in this field of rapidly emerging treatment options. 
The annual activity survey of the EBMT reflects current activity and trends in the field of transplant technology. It is valuable for the dissemination of the most recent information on indications, donor, and stem cell usage, which can ultimately be beneficial in health care planning.

Acknowledgements Special thanks go to the cooperation of all participating teams and their staff (listed in the online Appendix). The staff at the EBMT Co-ordination offices; Barcelona, Paris, London (C. Ruiz de Elvira), the national registries; the Austrian Registry (ASCTR) (H. Greinix and B. Lindner), the Belgium Registry (Y. Beguin and A. DeGeyndt), the Czech Registry (P. Zak and M. Trnkova), the French Registry (SFGM-TC) (J-O. Bay, N. Raus, and R. Chebel), the German Registry (DRST) (C. Müller, H. Ottinger, H. Neidlinger, S. Frank, and F. Hanke), the Italian Registry (GITMO) (F. Bonifazi and E. Oldani), the Dutch Registry (J.J. Cornelissen, M. Abrahanse-Testroote, and J. Refos), the Spanish Registry (GETH) (C. Solano and A. Cedillo), the Swiss Registry (SBST) (U. Schanz, H. Baldomero, and T. Demont), and the British Registry (BSBMT) (K. Orchard and J. Perry). The authors also thank D. John for database support.

\section{Compliance with ethical standards}

Conflict of interest The authors declare that they have no conflict of interest.

Publisher's note: Springer Nature remains neutral with regard to jurisdictional claims in published maps and institutional affiliations.

Open Access This article is licensed under a Creative Commons Attribution-NonCommercial-NoDerivatives 4.0 International License, which permits any non-commercial use, sharing, distribution and reproduction in any medium or format, as long as you give appropriate credit to the original author(s) and the source, and provide a link to the Creative Commons license. You do not have permission under this license to share adapted material derived from this article or parts of it. The images or other third party material in this article are included in the article's Creative Commons license, unless indicated otherwise in a credit line to the material. If material is not included in the article's Creative Commons license and your intended use is not permitted by statutory regulation or exceeds the permitted use, you will need to obtain permission directly from the copyright holder. To view a copy of this license, visit http://creativecommons.org/licenses/by-nc-nd/4.0/.

\section{References}

1. Copelan EA. Hematopoietic stem-cell transplantation. N Engl J Med. 2006;354:1813-26.

2. Appelbaum FR. Hematopoietic-cell transplantation at 50. N Engl J Med. 2007;357:1472-5.

3. Sureda A, Bader P, Cesaro S, Dreger P, Duarte RF, Dufour C, et al. Indications for allo- and auto-SCT for haematological diseases, solid tumours and immune disorders: current practice in Europe, 2015. Bone Marrow Transplant. 2015;50:1037-56.

4. Gratwohl A, Baldomero H, Aljurf M, Pasquini MC, Bouzas LF, Yoshimi A, et al. Hematopoietic stem cell transplantation: a global perspective. JAMA. 2010;303:1617-24.

5. Gratwohl A, Pasquini MC, Aljurf M, Atsuta Y, Baldomero H, Foeken L, et al. One million haemopoietic stem-cell transplants: a retrospective observational study. Lancet Haematol. 2015; ume 2 (No. 3):e91-100.
6. Gratwohl A, Baldomero H, Schwendener A, Gratwohl M, Apperley J, Frauendorfer K, et al. The EBMT activity survey 2008 impact of team size, team density and new trends. Bone Marrow Transplant. 2011;46:174-91.

7. Gratwohl A. Bone marrow transplantation activity in Europe 1990. Report from the European Group for Bone Marrow Transplantation (EBMT). Bone Marrow Transplant. 1991;8:197201.

8. Gratwohl A, Baldomero H, Horisberger B, Schmid C, Passweg J, Urbano-Ispizua A. Accreditation Committee of the European Group for Blood and Marrow Transplantation (EBMT). Current trends in haematopoietic stem cell transplantation in Europe. Blood. 2002;100:2374-86.

9. Gratwohl A, Baldomero H, Schwendener A, Rocha V, Apperley J, Frauendorfer K, et al. The EBMT activity survey 2007 with focus on allogeneic HSCT for AML and novel cellular therapies. Bone Marrow Transplant. 2009;43:275-91.

10. Gratwohl A, Schwendener A, Baldomero H, Gratwohl M, Apperley J, Niederwieser D, et al. Changes in use of hematopoietic stem cell transplantation; a model for diffusion of medical technology. Haematologica. 2010;95:637-43.

11. Passweg JR, Baldomero H, Peters C, Gaspar HB, Cesaro S, Dreger P, et al. Hematopoietic SCT in Europe: data and trends in 2012 with special consideration of pediatric transplantation. Bone Marrow Transplant. 2014;49:744-50.

12. Passweg JR, Baldomero H, Bader P, Bonini C, Cesaro S, Dreger $\mathrm{P}$, et al. Hematopoietic stem cell transplantation in Europe 2014: more than 40000 transplants annually. Bone Marrow Transplant. 2016;51:786-92.

13. Passweg JR, Baldomero H, Bader P, Bonini C, Duarte RF, Dufour $\mathrm{C}$, et al. Use of haploidentical stem cell transplantation continues to increase; the 2015 European Society for Blood and Marrow Transplant activity survey report. Bone Marrow Transplant. 2017;52:811-7.

14. Niederwieser D, Baldomero H, Szer J, Gratwohl M, Aljurf M, Atsuta $\mathrm{Y}$, et al. Hematopoietic stem cell transplantation activity worldwide in 2012 and a SWOT analysis of the Worldwide Network for Blood and Marrow Transplantation Group including the global survey. Bone Marrow Transplant. 2016;51:778-85.

15. World Health Organisation, WHO (http://www.who.int/topics/tra nsplantation/en/).

16. Passweg JR, Baldomero H, Bader P, Basak GW, Bonini C, Duarte $\mathrm{R}$, et al. Is the use of unrelated donor transplantation leveling off in Europe? The 2016 European Society for Blood and Marrow Transplant activity survey report. Bone Marrow Transplant. 2018;53:1139-48.

17. Gratwohl A, Passweg J, Baldomero H, Hermans J. Blood and marrow transplantation activity in Europe 1997. European Group for Blood and Marrow Transplantation (EBMT). Bone Marrow Transplant. 1999;3:231-45.

18. Schrezenmeier H, Passweg JR, Marsh JC, Bacigalupo A, Bredeson $\mathrm{CN}$, Bullorsky $\mathrm{E}$, et al. Worse outcome and more chronic GVHD with peripheral blood progenitor cells than bone marrow in HLA-matched sibling donor transplants for young patients with severe acquired aplastic anemia. Blood. 2007;110:1397-400.

19. Eapen M, Le Rademacher J, Antin JH, Champlin RE, Carreras J, Fay J. et al. Effect of stem cell source on outcomes after unrelated donor transplantation in severe aplastic anemia. Blood. 2011;118:2618-21.

20. Clay J, Kulasekararaj AG, Potter V, Grimaldi F, McLornan D, Raj $\mathrm{K}$, et al. Nonmyeloablative peripheral blood haploidentical stem cell transplantation for refractory severe aplastic anemia. Blood Marrow Transplant. 2014;20:1711-6.

21. Young NS. Aplastic anemia. N Engl J Med. 2018;379:1643-56. 
22. Esteves I, Bonfim C, Pasquini R, Funke V, Pereira NF, Rocha V, et al. Haploidentical BMT and post-transplant $\mathrm{Cy}$ for severe aplastic anemia: a multicenter retrospective study. Bone Marrow Transplant. 2015;50:685-9.

23. DeZern AE, Zahurak M, Symons H, Cooke K, Jones RJ, Brodsky RA. Alternative donor transplantation with high-dose post-transplantation cyclophosphamide for refractory severe aplastic anemia. Biol Blood Marrow Transplant. 2017;23:498-504.

24. Bonini C, Mondino A. Adoptive T-cell therapy for cancer: the era of engineered T cells. Eur J Immunol. 2015;45:2457-69.
25. Tolar J, Le Blanc K, Keating A, Blazar BR. Concise review: hitting the right spot with mesenchymal stromal cells. Stem Cells. 2010;28:1446-55.

26. Snowden JA, Badoglio M, Labopin M, Giebel S, McGrath E, Marjanovic Z. Evolution, trends, outcomes, and economics of hematopoietic stem cell transplantation in severe autoimmune diseases. Blood Adv. 2017;1:2742-55.

27. Maude SL, Frey N, Shaw PA, Aplenc R, Barrett DM, Bunin NJ, et al. Chimeric antigen receptor $\mathrm{T}$ cells for sustained remissions in leukemia. N Engl J Med. 2014;371:1507-17. 